\title{
Re-reading the future of work
}

\author{
Colin C. Williams ${ }^{1}$
}

How will work be organized in the future? This paper challenges and explodes many popular myths that constrain how we envisage the future of work. Grounded in a geographically global focus, it provides not only a critical overview of the array of competing visions but also a radical rethink of the direction of change. The result is to transcend the conventional dominant narratives about the trajectory of work and to open up the future of work to alternative regimes of representation and practice in order to imagine and enact other futures for work beyond formalization, commodification and globalization. [Article copies available for a fee from The Transformative Studies Institute. E-mail address: journal@transformativestudies.org Website: http://www.transformativestudies.org (02009 by The Transformative Studies Institute. All rights reserved.]

KEYWORDS: Future of Work, Economic Development, Work Organization, Globalization, Commodification, Informal Economy, PostFordism, Post-Bureaucracy.

\section{INTRODUCTION}

There are multiple visions of the future of work. Indeed, there seem to be as many visions as there are commentators. In some visions, the future of work is rosy; in others it is full of despair. In some commentaries, moreover, radical changes are about to take place; in others, the future will be

\footnotetext{
${ }^{1}$ Colin C. Williams is Professor of Public Policy in the School of Management at the University of Sheffield in the United Kingdom. His books include The Hidden Enterprise Culture (2008, Edward Elgar), Re-thinking the Future of Work (2007, Palgrave-

Macmillan) and Cash-in-Hand Work (2004, Palgrave-Macmillan). His interests are in rereading the future of work and trajectories of economic development in order to open up the future to alternative possibilities. Address correspondence to: Colin C. Williams, Professor of Public Policy, School of Management, University of Sheffield, 9 Mappin Street, Sheffield, United Kingdom S1 4DT; tel: +44 114222 3476; e-mail:

C.C.Williams@sheffield.ac.uk.
} 